\title{
Action Research on Exploring the Effectiveness of Continuous Assessment on English Common Course in a Case of Plant Science Year I Students Aksum university Shire Campus
}

\author{
Mr. Mihiretu Wakwoya Tolosa \\ Researcher and Lecturer \\ Department of English Language and Literature \\ College of Social Sciences and Humanities \\ Dambi Dollo University \\ Dambi Dollo, Oromiya, Ethiopia \\ mihiretu2005@gmail.com
}

\begin{abstract}
This action research was aimed mainly to investigate the effectiveness of continuous assessment in English common course in case of students of plant science first year program at shire campus. The study involved $55(\mathrm{M}=15, \mathrm{~F}=40)$ students and $7(\mathrm{M}=4, \mathrm{~F}=3)$ English common course instructors as participant of the study. It also employed three data gathering tools: questionnaire, interview and document analysis. Data obtained from these multisource were analyzed quantitatively and qualitatively in which case percentage and verbal description were used respectively. Hence, the finding indicates that there were no bolded theoretical and practical implementation gaps of CA among instructors and students. However, many impressing factors were found, which impede the implementation of CA.
\end{abstract}


Among these, large number of students in a section, instructors' workload, students' attitudes toward CA, lack of specific criteria for checking subjective form of students' assignment and project work were some. Generally, the study attempts to forward action to be taken to tackle the problem, such as lessen teachers' workload, minimizing number of students in one section accordance with MEO policy, proposing clear-cut criteria for checking and giving feedback for subjective case assignments. Moreover, instructors need to motivate students to work or involve in $\mathrm{CA}$ as well as committed themselves to implement effectively that contributed to prove quality of education.

Keywords: Continuous Assessment, Effectiveness, Exploring.

\section{Introduction}

Continuous Assessment defined by different scholars from different angles that can be categorized as narrow and broad definitions. The narrow definition limits Continuous Assessment only to classroom instruction. For instance, as Asabe (2007), a classroom process integrated with instruction. Similarly, Falayalo (1986) and Juliet (2007), viewing it as a fundamental part of instruction, considers it as a mechanism whereby the final grading of learners on the cognitive, affective, and psychomotor domains of learning is made. The cognitive domain refers to the development of students' content knowledge and intellectual skills, while the affective domain includes students' confidence, feelings, values, motivations and attitudes. The psychomotor domain refers to the physical movement, coordination and use of motor skills; and in this study, it is particularly related to students' speaking and writing skills. Continuous assessment is a classroom strategy implemented by teachers to ascertain the knowledge, understanding, and skills attained by pupils (USAID, 2003). 
Ethiopian universities have experienced heavy use of traditional summative that is more judgmental approaches. The assessments have been considered as the numerical summation of tests and final examinations rather than how know of students' knowledge respect to subject matter. These methods of assessment are failed in critiques because of its negligible role of determining student development (Puhl, 1997). Contemporarily, there misperceived way of assessment shifted to gauge performance to a more dynamic alternative of determining "what learners know and can do" (Puhl, 1997: 2). The shift is influenced by the underlying assumption that assessment processes change instructional processes because of learning. Gravaso (2002) study confirmed this correlation of assessment and instruction at a university context.

In outcome-based education, continuous assessment plays a pivotal role. As stated in the Ethiopian Education Policy (ETP, 1994) and millennium Educational development goal, the teaching/learning process targets an outcome-based education that will invest on problem solving, evaluation, creativity, and deeper learning. To achieve these critical thinking skills, the Policy has also stated that a concerted effort should be made to marry instruction and assessment; that is, continuous assessment. Continuous assessment enables teachers to develop students' psychological, intellectual, physical and social interaction skills. Continuous assessment in academic and practical subjects including aptitude test was/were conducted to ascertain the formation of all-rounded profile of students Schools in Ethiopia now practice continuous assessment.

Continuous assessment has benefits and limitations. First, it is advantageous because it regularly illuminates about the quality of teaching and learning and informs about the level of students' achievement of learning objectives and expected competencies. Continuous assessment allows teachers to better employ the teaching-assessment-feedback-correction (reteaching) learning cycle that summative, time-limited evaluations lack (National Institute for 
Educational Development (NIED), 1999:8). In this paradigm, instruction and assess-ment are seamless in the teaching process: one leading to the other (ibid). Similarly, Alausa (2006) regards continuous assessment as guidance-oriented because it gathers data about the teaching/learning over a period and helps modify instruction.

CA is beyond the summation results of student's marks. It is the method in which teacher evaluates how the intended objectives of the course achieved, to what extent students understand and like. Taking these as benchmark teachers make revise of methods of teaching; techniques of evaluation, teaching aids and materials used. Regarding these Nitko (2004), as cited in Adebowale and Alao (2008), described it as an information-gathering tool that helps teachers select content and method of instruction.

Continuous Assessment is an ongoing process of gathering and interpreting information about student learning that is used in making decisions about what to teach and how well students have learned (p.4).

Contrary to these, the researchers have been experienced that the total results of students are high but when they become to practical situation the cumulative CA does not demonstrate to the extent the students gained knowledge. Then, the researchers are initiated to carry out this action research entitled assessing effectiveness of CA on English course in a case of Plant Science year I students.

However, for the fact that this concept is new trend, do instructors actually continuously assess with the intended instruction and its smart objectives? Since teachers' and students' actions are highly influenced by their beliefs (Abiy, 2000, 2002; Cain, 2012; Fang, 1996; Vibulphol, 2004; Wittrock, 1986), this study wants to assess University teachers' and students' perceptions of continuous assessment and their classroom application. Thus, the study was going tosolve the problem of CA on English common course in a case of Plant Science year I students having main objective of assessing effectiveness of CA on English 
course in a case of Plant Science first year students. Put clearly, this study attempts to respond to the following research questions: Are there gaps between theoretical and practical principles of CA among the teachers? What are factors that impede implementations of continuous Assessment?

This study has theoretical and practical value. Especially, it primarily benefits instructors and trainees of plant science department as whole and particularly common course English language instructors and students those will offer these courses to cope with effective CA methods in actual classroom situation. In addition, the instructors would gain better insight about CA. Furthermore, the study would serve as a reference for researcher who is in need of conducting in similar or same area of this study.

The study focused only to Aksum University Shire Campus first year students of Plant Science Program and instructors those teach them because of time, finance and human powers. The study examined merely the effectiveness of CA. Over all the action taken was/were confined to specified particular area.

This study is believed to have certain limitations because of time, human power and financial constraints. However, the study would have been more comprehensive if more sections had been included from other departments. In addition, most of randomly selected respondents for students' questionnaire failed to respond to the open-ended questions that required their free responses. Because of these and other variables, the result of the research could be affected in one way or other. Thus, the findings, which are the basis for actions to be taken, are not supposed to be free from limitations. Therefore, the researchers do not claim the completeness of the study. 
2. Methodology of the study

The study included plant science teachers particularly who teach total of $(\mathrm{M}=4, \mathrm{~F}=3)$ the section under the study and one section of students of first year 2017 entry of plant science program total $55(\mathrm{M}=15, \mathrm{~F}=40)$.

First year student was selected purposively because English common course was given for fresh student and plant science program was selected because of the fact that in which the researchers have been more experienced the problem under the investigation. Similarly, lecturer of plant science and English common course lecturer were chosen because they have been taught the class at the time of the study.

This section contains different methods of relevant data gathering instrument. These instruments are: Interview was felt suitable for the study to capture or tap true witness by face-to-face interaction about perceptions of teachers. In addition, the subjects with whom the interview was conducted were few in which case an interview was appropriate. Therefore, a semi structured interview was set to collect pertinent information from instructors and key informant from students.

The interview was consisted of open-ended question that were followed by probing questions. Questionnaire was employed to elicit data from $55(\mathrm{M}=15, \mathrm{~F}=40)$ student respondents. It was used for its simplicity and appropriate to gather securing pertinent information early from many respondents. It comprised two sections. The first section was closed-ended items whereas the second section was open-ended.

As one of data collection instruments, document analysis was used to assess whether the contents of the students' assignment are appropriately checked or whether there were any criteria for giving mark or not. Therefore, sample-assignments and project work were analyzed based on proposed criteria and checklist. 
The data gathered through the instruments repeatedly stated earlier, were thematically organized, interpreted and analyzed qualitatively and quantitatively .Then tables were used and illustrated. Finally, all data obtained from different sources were triangulated to arrive at sounded action to be taken.

3. Data analysis /result and discussion

First, the quantitative analysis of fixed-response items is presented and then, consolidated with the corresponding themes arising from qualitative data with respect to each of the action research objectives accordingly.

\begin{tabular}{|lcccc|}
\hline Items & & & & \\
& No & $\%$ & No & $\%$ \\
& 39 & 86.7 & 6 & 13.3 \\
\hline Item 2 & 35 & 77.8 & 11 & 22.2 \\
\hline Item 3 & 40 & 88.8 & 5 & 11.2 \\
\hline Item 4A & 41 & 91.1 & 4 & 8.9 \\
\hline Item 4B & 38 & 84.4 & 7 & 15.6 \\
\hline Item 4C & 32 & 71.1 & 13 & 28.9 \\
\hline
\end{tabular}

Table 1. Students' response on questionnaire Objective One -To find out gaps between theoretical and practical principles of CA among the teachers.

As can be seen from Table 1, the table displayed seven items, which is supposed to be what teachers perform in actual classroom respect to theoretical principles of continuous assessment. Accordingly, item 1 attempts to identify if teachers assess students' progress or not and the analysis show that $86.7 \%$ rate 'yes' and $13.3 \%$ rate 'No'. In addition, $80 \%$ of the theme interview reveals that teacher assesses their progress of understanding continuously rather than periodically. 
Similarly, the theme of teacher's interview confirms this idea. As a result, it can be simply said to be teacher assess students progress continuously.

Item two tries to discover whether the teacher use various way of assessing techniques or not. For this $77.8 \%$ respond 'Yes' that indicate teachers use different techniques of assessing such as quiz, individual and group assignment, class work and home take assignments, etc., whereas

$22.2 \%$ responded 'No' that show as teachers did not use different techniques of assessment. Furthermore, the theme of students key informant interview (90\%) prove that teacher use various methods of continuous assessment, like oral presentation, quiz, assignments, etc. Likewise, the theme of teacher's interview also verified this idea.

Item 3 is at checking if continuous assessment preferable than mid exam or final exam. Then $88.8 \%$ of students replied 'Yes' while $11.2 \%$ said 'No'. Similarly, majority of key informants of interview indicate that continuous assessment is more valuable than mid or final examination. In the same way teacher also witnessed as continuous assessment is paramount important than other summative assessment. Then one can simply understand that continuous assessment is more advantageous than other periodical assessment.

Generally, taking majorities responses and document analysis, the analysis revealed that there is no significant gap between theoretical and practical situations of continuous assessment in real world. However, what matter most in continuous assessment is the way to manage, and the techniques used face problem. These is because of the fact that the teachers use the same methods of assessment through the semester, for example teachers maximize quiz which is given at the end of certain lesson and marginalize techniques like classroom activities, such as class work, oral question, presentation, etc.

Objective Two-To examine factors those impede implementation of continuous assessment 
Numbers of factors can affect effectively implementation of CA that related teachers and students. Therefore, item 4 with its sub question in questionnaire, open-ended questionnaire and interview question item 7 as well as document analysis tried to test this issue. Hence, the followings are discussion and analysis of it.

Item 4A attempts to identify whether large class size or above average number of students in a class does have impact or not on conducting continuous assessment. Thus, almost $91 \%$ of respondents say 'yes' while very few respondents (9\%) responded 'No'. Similarly, around $94 \%$ of students on item 6 in the open ended listed as large number of students in one class does have effect on continuous assessment and only $6 \%$ responded as it has no effect. Therefore, it can be understood from these students response as the large numbers of students do have impact on effective implementation of continuous assessment. In the same way, theme of document analysis and interview also support this.

In addition, Item 4B goes on to check if time has influence on continuous assessment, and $84.4 \%$ of students replied 'Yes' whereas $15.6 \%$ 'No'. Also, $80 \%$ of students listed out on open ended question item 6 as time is one of factor for implementation of CA. Then, one can judge from the analysis that constraint of time has negative effect on implementation of continuous assessment. Moreover, the theme of the interview and the document analysis in relation to number of students in one section indicate that lack of enough time does have its own effect on its implementation.

The last item 4C assesses whether clear cut criteria exists to check students subjective Assignment. For this item, almost $71 \%$ of respondents replied 'Yes' while almost $29 \%$ said 'No'. In the same way, $79 \%$ of the theme of open-ended questionnaire indicates that lack of clear-cut criteria to gauge most students' subjective assignments. Therefore, it can be affirmed that absence of clear-cut criteria while checking students' written assignment is the 
other major problem on effectiveness of continuous assessment. Likely, the theme of document analysis confirms this.

Overall, concerning the factor impede implementation of continuous assessment the majorities' responses and document analysis indicates that large number of students in a section, teacher's workload and lack of clear-cut criteria to check students' assignment are some of the impressing factors. In addition, students' interest and teachers' commitment are other contributing factors.I

\section{Actions to be taken}

In light of the action research finding, actions to be taken are forward accordingly.

$\Rightarrow$ Classroom verses to students number ratio need to be adjusted accordance with MOE to make manageable size of student in a section.

$\Rightarrow$ In the same way, Teacher ratio with sections ratio should match accordance with MOE policy to lessen teachers burden

$\Rightarrow$ Amend criteria for checking students assignment properly by giving weight for each criteria, for instance if the assignment is focus on improving writing skills of student using grammar error, spelling error, punctuation error, organization of the paper, clear and readable handwriting, etc, and if the assignment focuses on improving speaking skills- using criteria, like how know of the issue, fluency, accuracy, clarity of pronunciation, etc

$\Rightarrow$ For using various techniques of continuous assessment preparing experience sharing stage, capacity building in staff training, inviting guests those endowed with the profession as well as seeking NGOs that sponsor seminars and workshop training. 


\section{Acknowledgement}

First, I would like to thank It is also our pleasure to acknowledge Dr. Hayelom Baro, for assisting me in this action research preparation and his patience in providing genuine ideas in my interview questions. In addition, it is also my pleasure to acknowledge students of first year Plant Science program for their volunteer participation in this action research being as target groups. Finally yet importantly, my extended gratitude also goes to authors of the reference books I used for this action research. Overall, I acknowledge those contributed their ideas and moral support directly or indirectly for the success of the study. 


\section{References}

Abiy Y (2000). 'Expressed beliefs and actual classroom practices of high school English teachers concerning error correction.' Ethiop. J. Educ. 20(1):91-109.

Abiy Y (2002). 'Competency beliefs, teaching confidence and teaching performance of English major graduating students in teaching practice.' Ethiop. J. Educ. 22(1):85109.

Alausa YA (2006). 'Continuous assessment in our schools: advantages and problems.'

Retrieved November 11th, 2006 from:

http://www.ednet.na/Resouces/Reform\%20Forum/journal9/ journal\%209\%

Article\%202.pdf.

Asabe MB (2007). Effects of continuous assessment on academic achievement of NCE. A thesis submitted to the postgraduate school in partial fulfillment of the requirements for the award of the degree of master of education chemistry

Cain M (2012). 'Beliefs about classroom practice: a study of primary teacher trainees in Trinidad and Tobago'. Int. J. Human. Soc. Sci. 2(3):96-105.

Education and Training Policy (ETP) (1994). Federal Democratic Republic of Ethiopia,Addis Ababa, St. George Printing Press.

Fang Z (1996). 'A review of research on teacher beliefs and practices.' Educ. Res. 38(1):4765.

Falayalo W (1986). Philosophy and theory of continuous assessment. A paper presented at a workshop for Inspectors of Education in Odor State, Nigeria. 4th December.

Gravaso RS (2002). Influence of students' learning experiences, learning conceptions and approaches on their learning outcomes pp.282-289 
Juliet OA (2007). A survey of the implementation of continuous assessment in Nigerian universities, a paper presented at second regional conference of higher education research and policy network (herpnet) held at II 1a Ibadan, Nigeria.

National Institute for Educational Development (NIED) (1999). Towards improving continuous assessment in schools: a policy and information guide for implementation, Republic of Namibia

NitkoAJ (2004). 'Continuous assessment and performance assessment.' Retrieved Nov. 11, 2006 from http://www. moec.gov.jm.pdf

Puhl CA (1997). 'Develop, not judge. Continuous assessment in the ESL classrooms.' Forum Online 35(2).

USAID (2003). 'Continuous assessment.' EQ Review, Educ. Qual. Dev. World 1(1):1-3.

Vibulphol J (2004). Beliefs about language learning and teaching approaches of pre-service EFL teachers in Thailand, Oklahoma State University (Unpublished $\mathrm{PhD}$ Dissertation) 